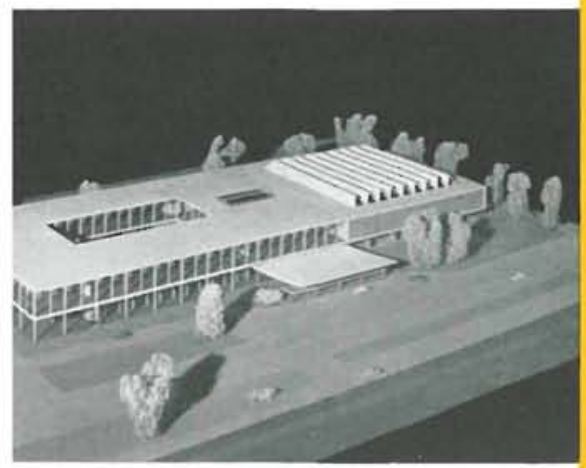

\title{
Wiesbaden
}

\section{sala \\ le espectáculos}

$146-54$
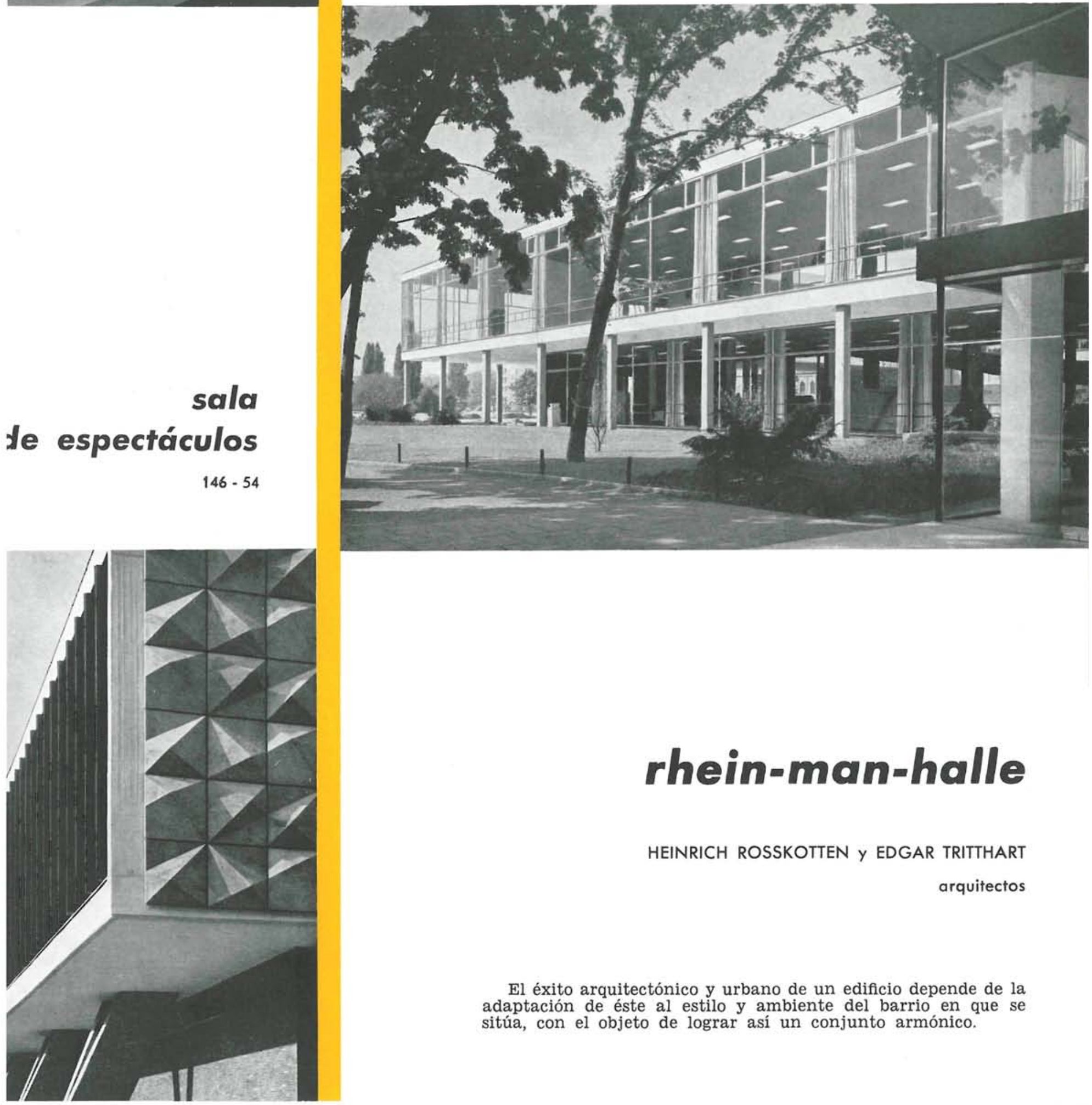

\section{rhein-man-halle}

HEINRICH ROSSKOTTEN y EDGAR TRITTHART

arquitectos

El éxito arquitectónico y urbano de un edificio depende de la adaptación de éste al estilo y ambiente del barrio en que se sitúa, con el objeto de lograr así un conjunto armónico. 


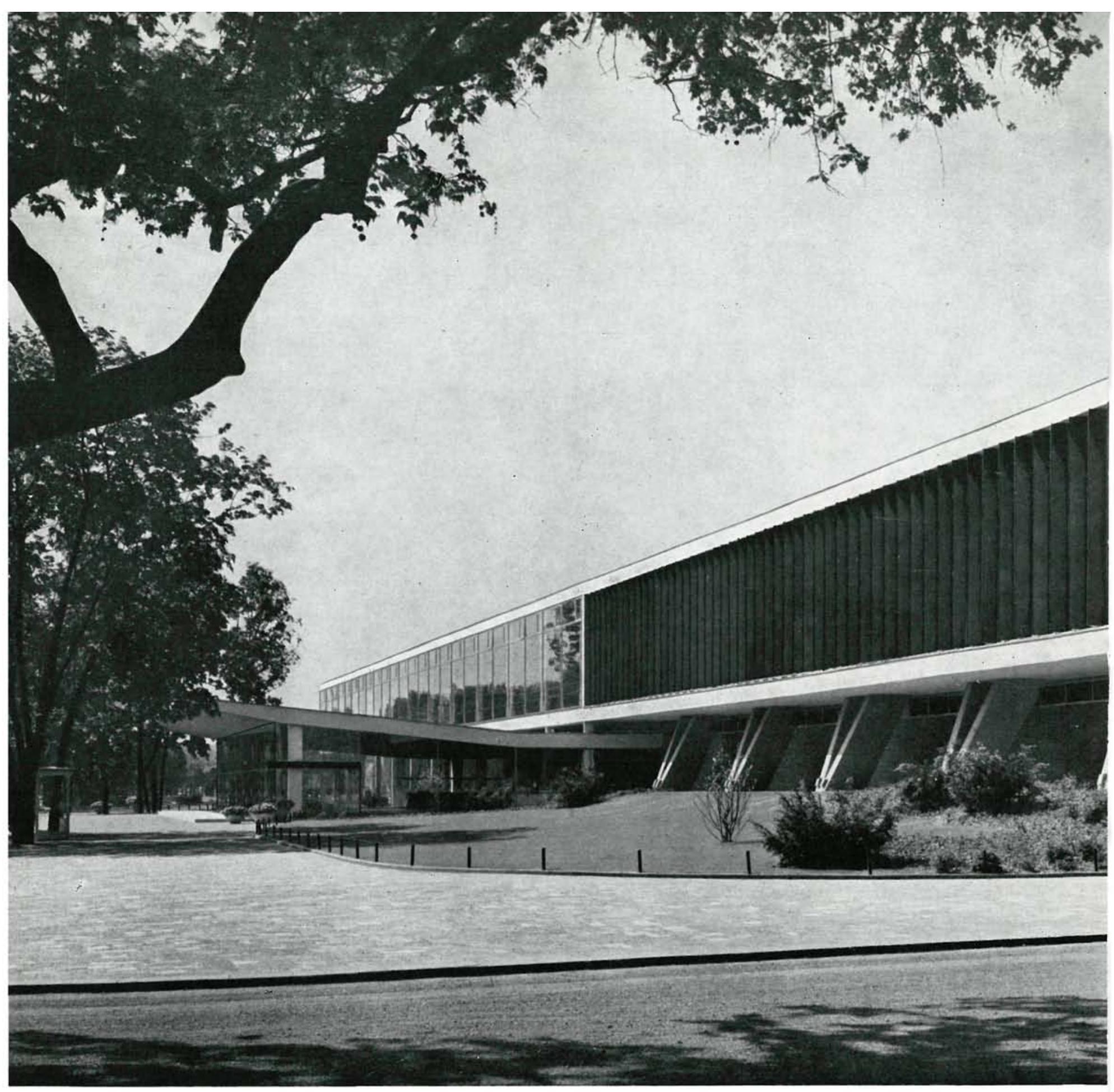

pla $n$ ta de situación

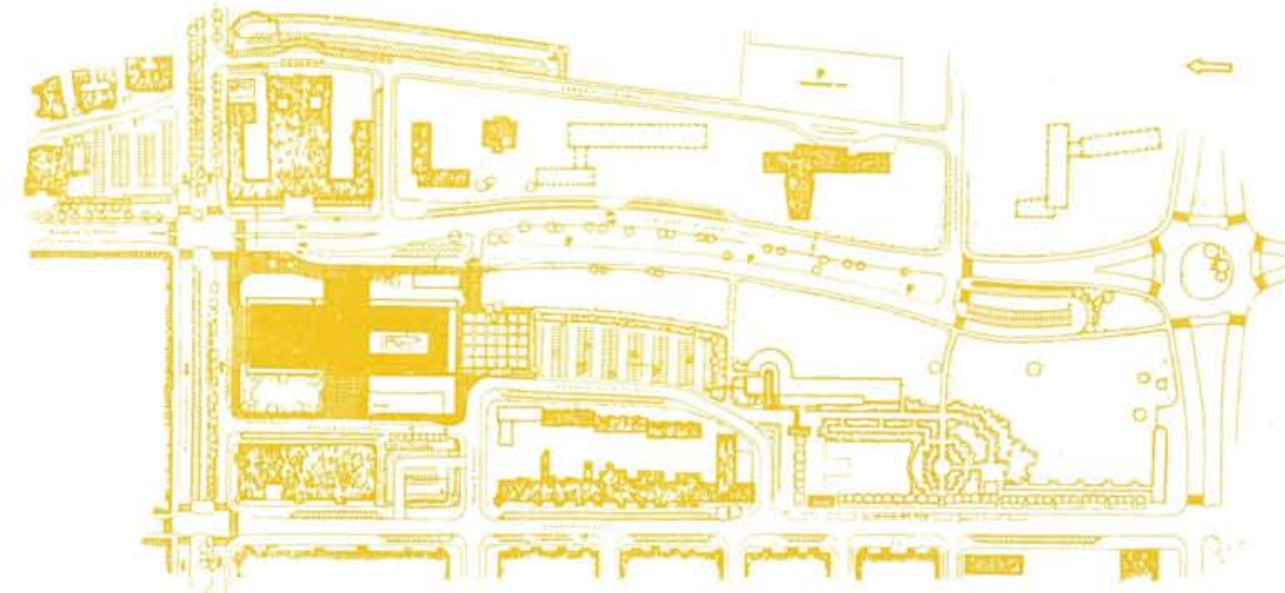



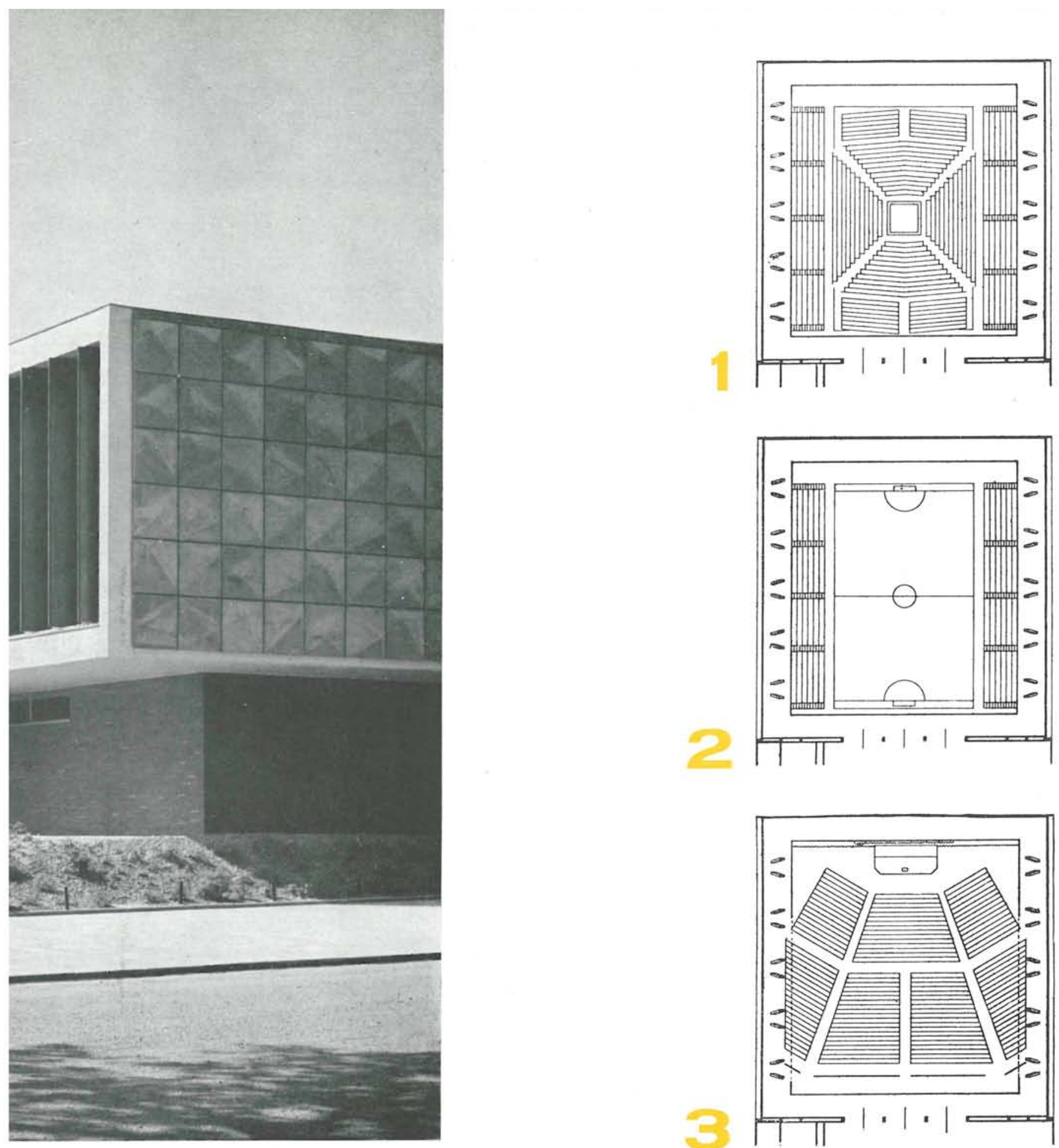

Las consideraciones básicas para la ejecuin de este proyecto no fueron las de loar una estructura más o menos atrevida zomo suele suceder en este tipo de consrcciones- sino las de conseguir un edifi, que se adaptara al conjunto de la ciudad, i negar por ello su propia personalidad. nto los elementos horizontales y verticacomo el tratamiento de las fachadas, bían expresar a todas voces el carácter 1 edificio. Otra premisa que hubo que te$r$ muy en cuenta, fué la del emplazamiento zona verde de este Rein-Main-Halle. Y, efecto, todos estos factores han sido ornados correctamente por el arquitecto sskotten, logrando un conjunto sincero, icional y lleno de plasticidad y armonía.
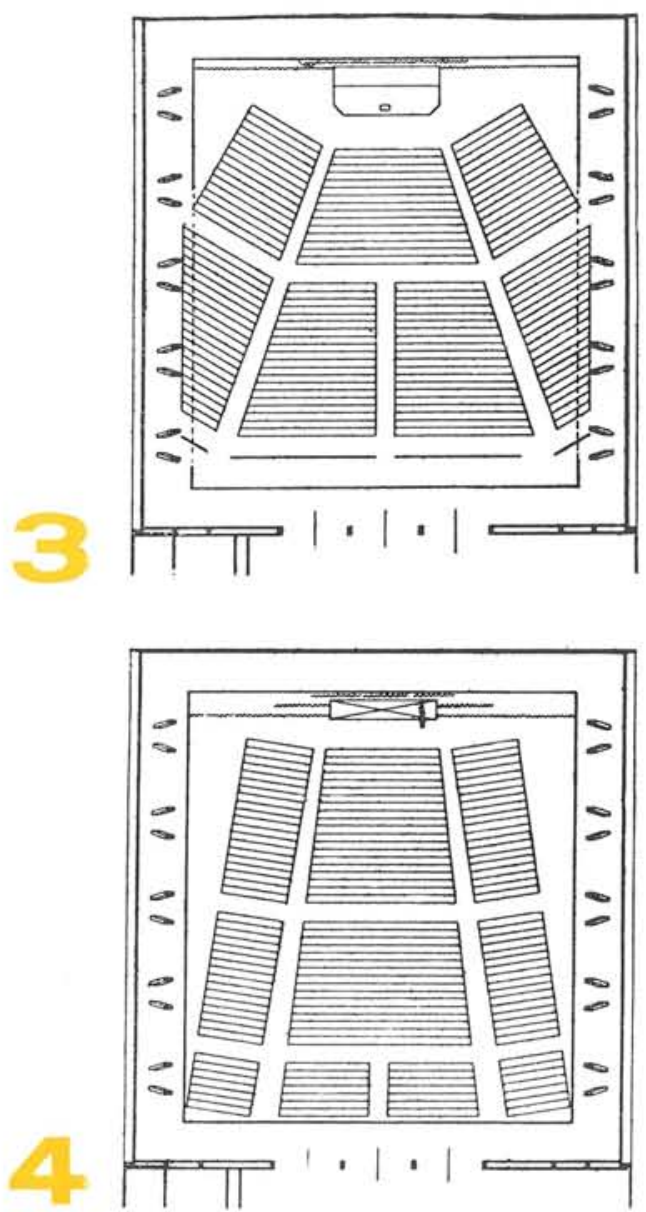

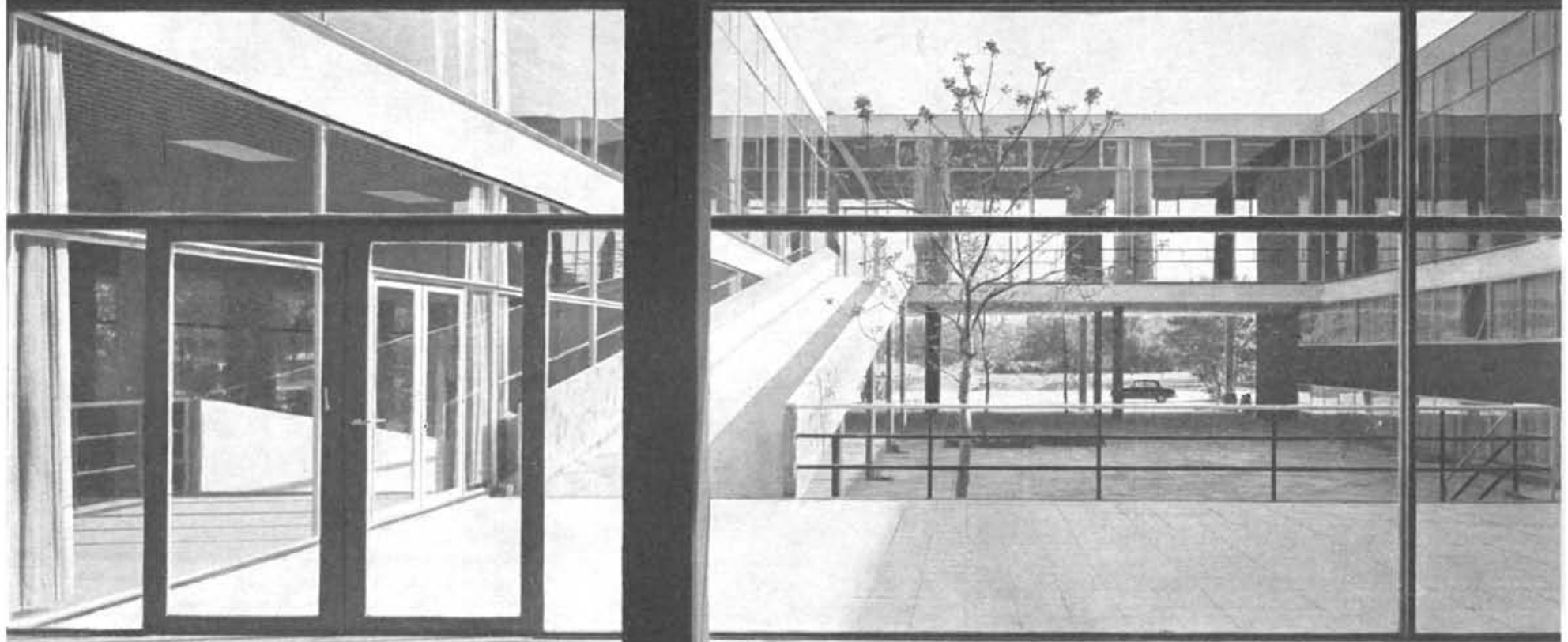

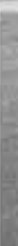

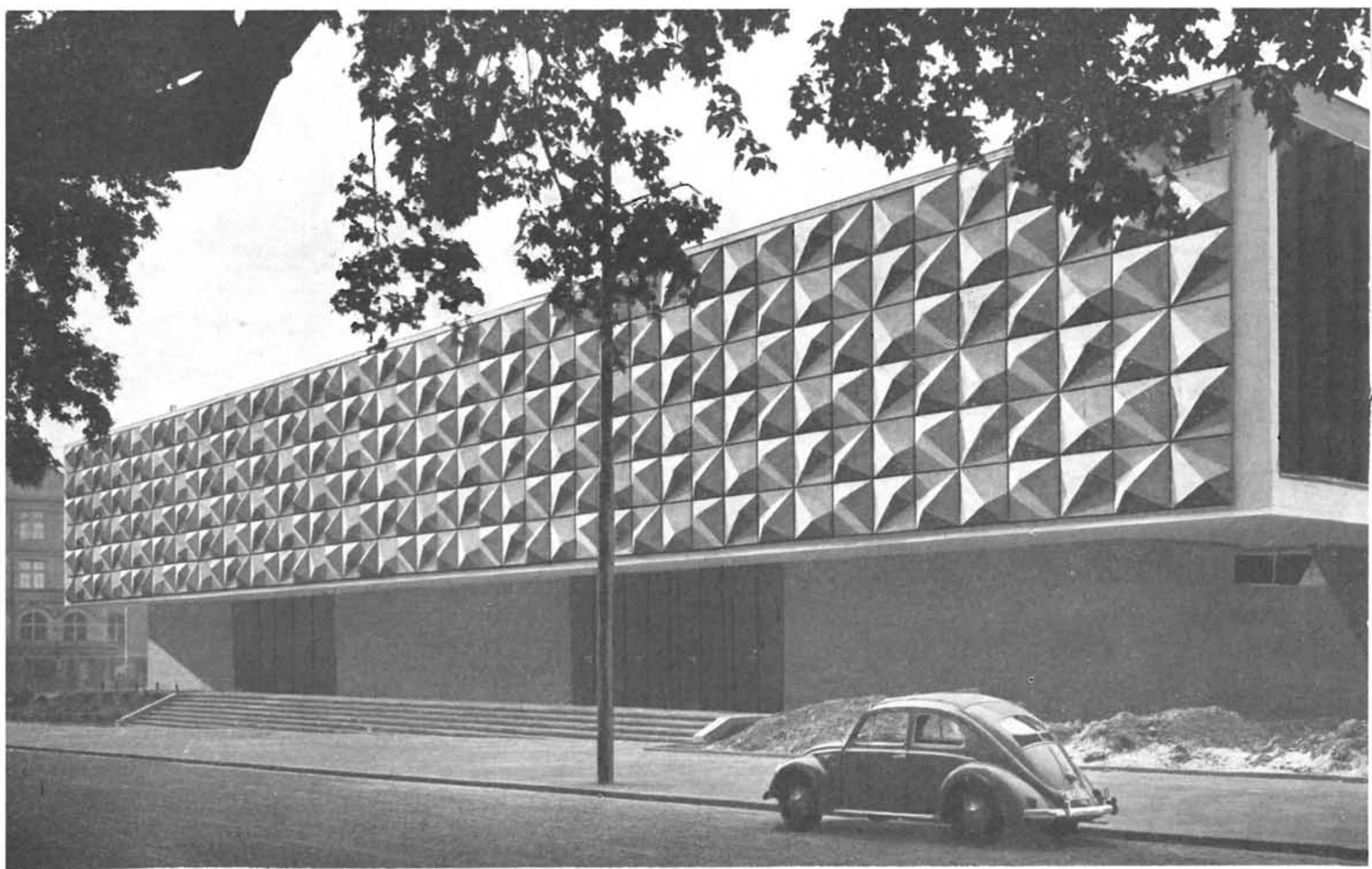



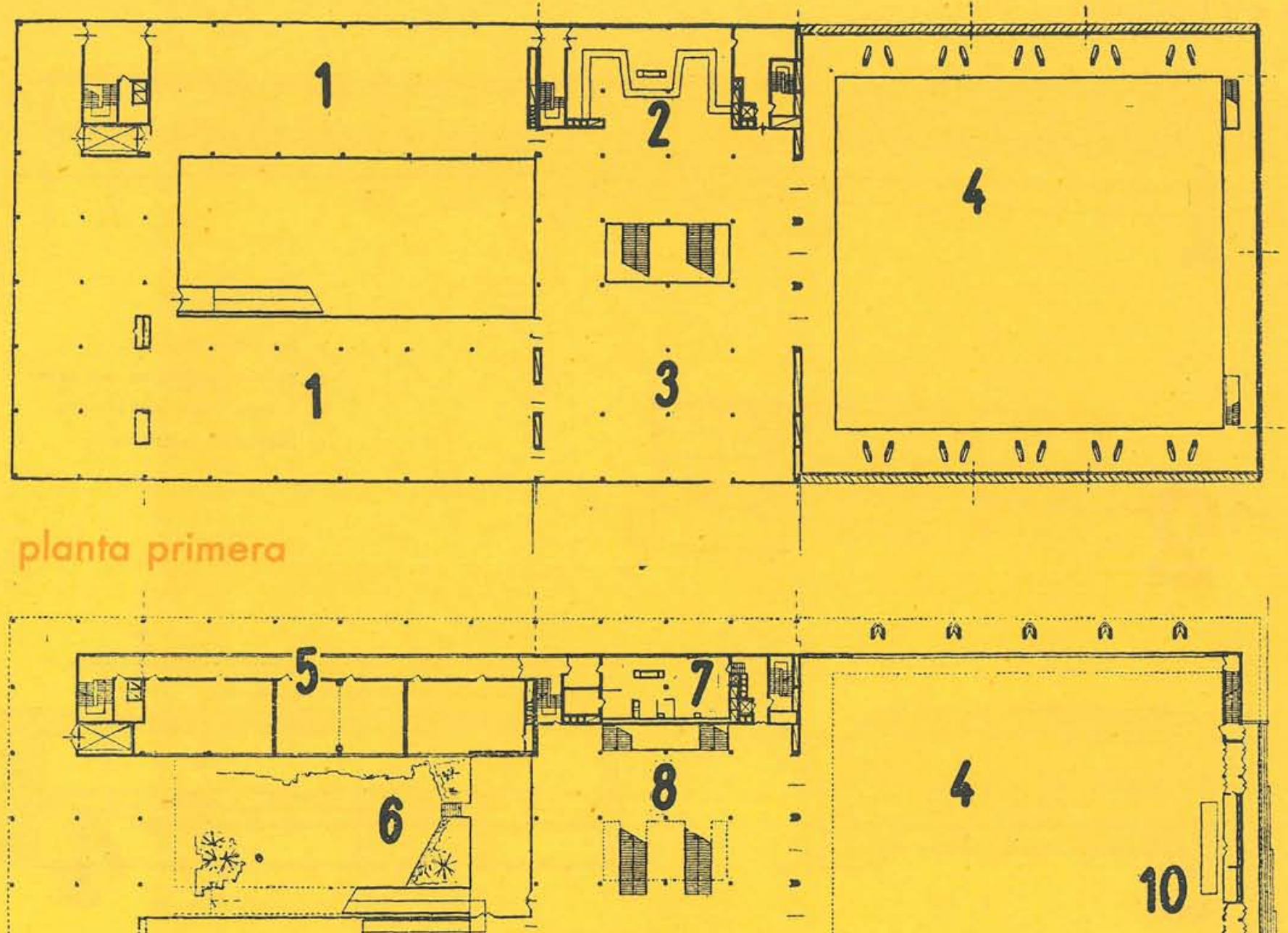

ค คิ คิด ค

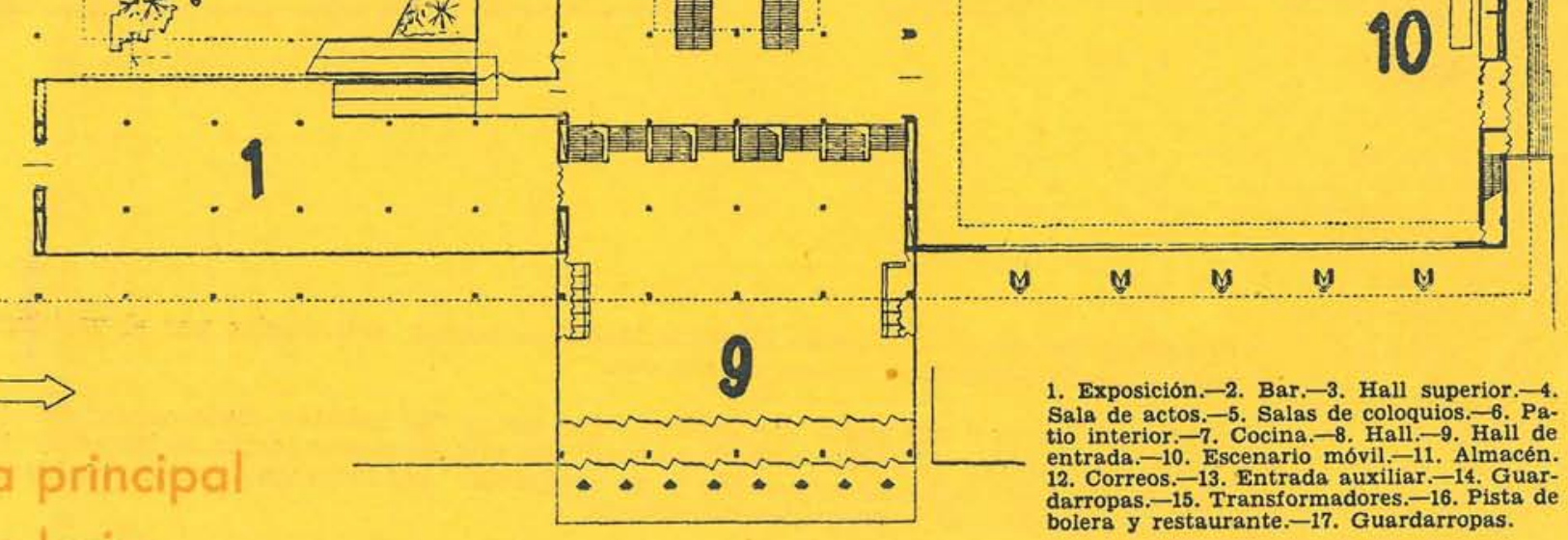

\section{planta baja}

darropas. -15 . Transformadores. -16 . Pista d

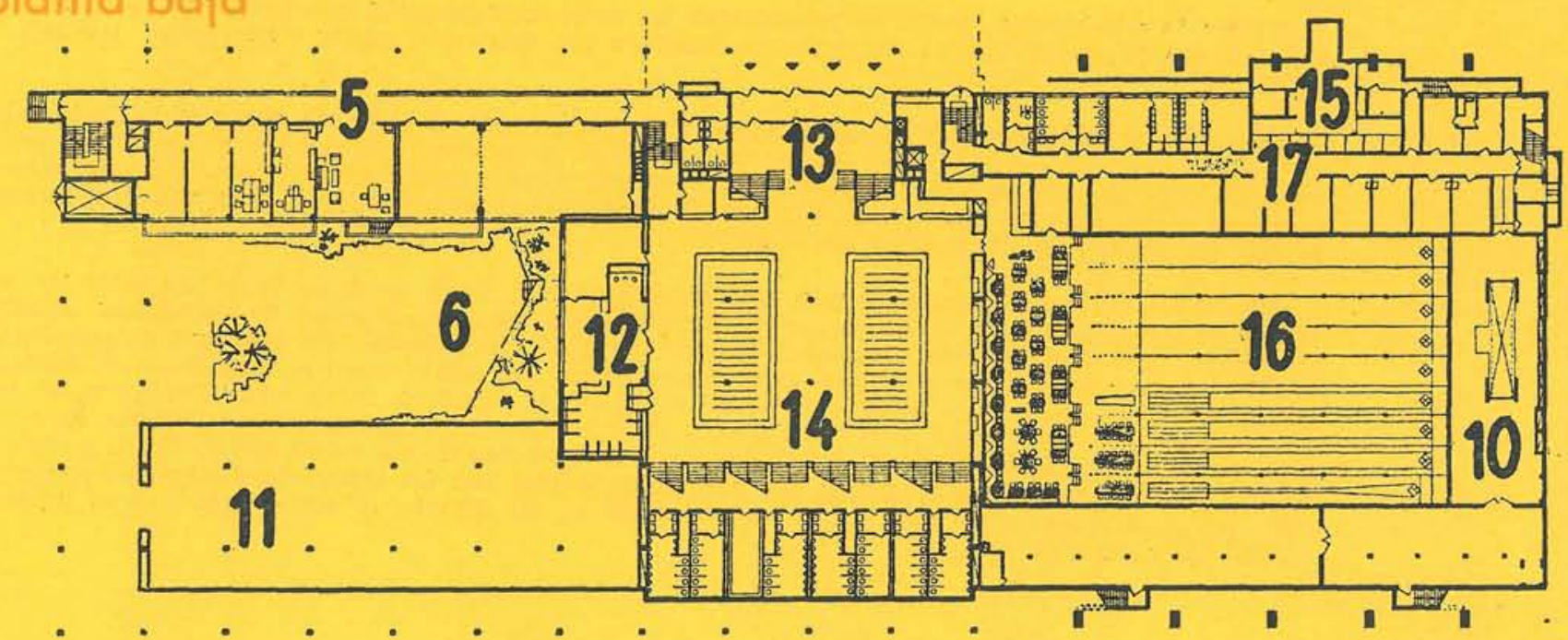



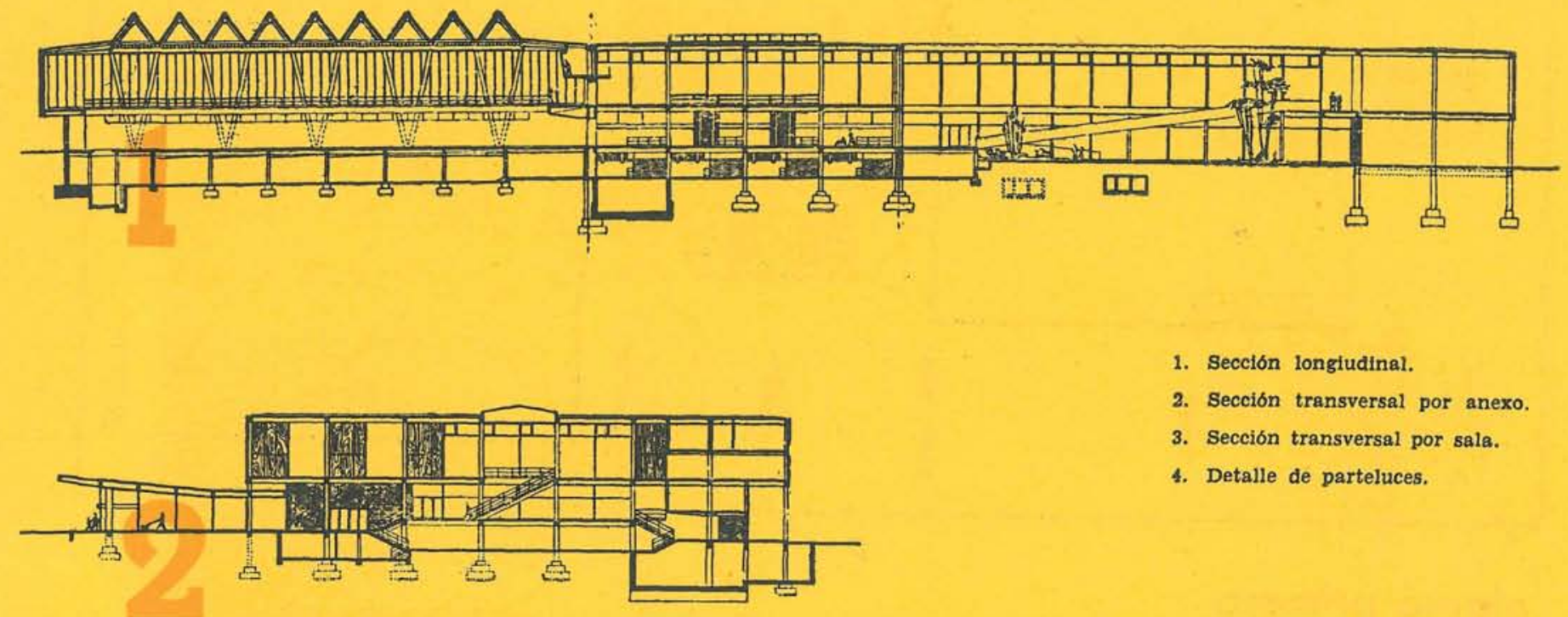

1. Sección longiudinal.

2. Sección transversal por anexo.

3. Sección transversal por sala.

4. Detalle de parteluces.
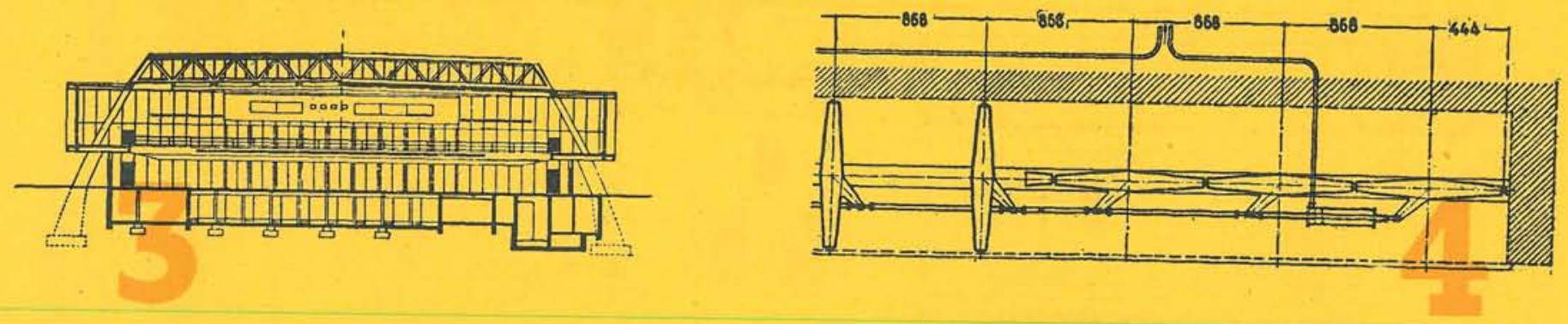

El edificio consta de dos zonas claramente determinadas, articuladas por el vestíbulo común a ambas: zona de exposición y zona de reunión.

Debido al desnivel del solar, el vestíbulo, que ocupa dos plantas, tiene acceso desde dos entradas opuestas situadas en calles a distinto nivel. En este elemento común se han dispuesto, además de los accesos a las salas de exposición y de congresos: guardarropas, aseos, restaurantes, oficinas, kioscos de revistas y despacho de correos.

Al sur de este bloque central se encuentran las salas de exposición con grandes superficies acristaladas que proporcionan al visitante el descanso que supone el poder contemplar el parque circundante.

Como contraposición a este efecto ligero y transparente, en la parte norte se halla la sala de congresos y conferencias, con su gran representación arquitectónica debido a los cinco grandes soportes y al acento de la fachada de ventanas que está subdividida por parteluces de acero. La fachada norte muestra un acento acusadamente plástico, subrayando, de esta manera, la importancia del edificio en la imagen de la calle.

Al proyectar Rosskotten esta sala con capacidad para 4.000 personas, tuvo que tener en cuenta el que se pudiera reducir en un momento determinado, ya que, además de celebrarse congresos, se debían prever conciertos, festivales, proyecciones de cine, desfles de modelos, actuaciones deportivas, sesiones de baile e incluso exposiciones. Por esta razón, todo el mobiliario es desmontable y, mediante cortinas y pantallas, puede reducirse el volumen de la sala disminuyendo su capacidad de 4.000 personas a 1.000. El sistema acústico de esta sala consiste en láminas de madera, llegándose a valores absorbentes de 0,25-0,8 con frecuencias de 125 hasta 400 Hertz. Los parteluces de las dos fachadas longitudinales del auditorio no sólo son un elemento decorativo importante, sino que controlan la entrada de la luz evitando el sol directo, y son también una protección contra los ruidos de la calle. 
Para dar una idea de la capacidad de absorción de público con que cuenta este hall, y para hacernos una idea de sus proporciones, citaremos algunos datos de superficie:
Sala de exposiciones: $4.400 \mathrm{~m}^{2}$
Vestíbulo superior:
$1.200 \mathrm{~m}^{2}$
Sala de congresos: $\quad 2.000 \mathrm{~m}^{2}$
Guardarropas:
$700 \mathrm{~m}^{2}$

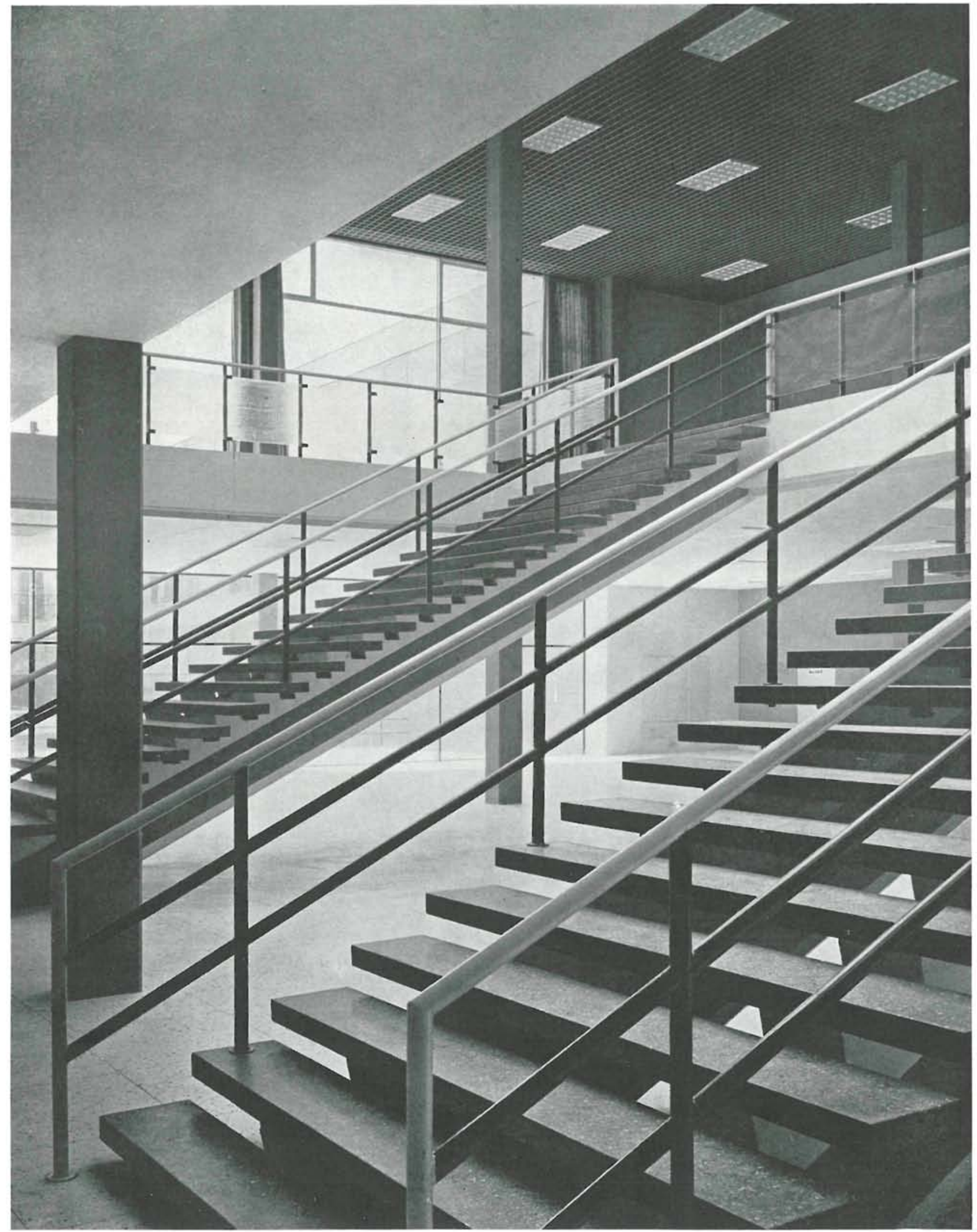




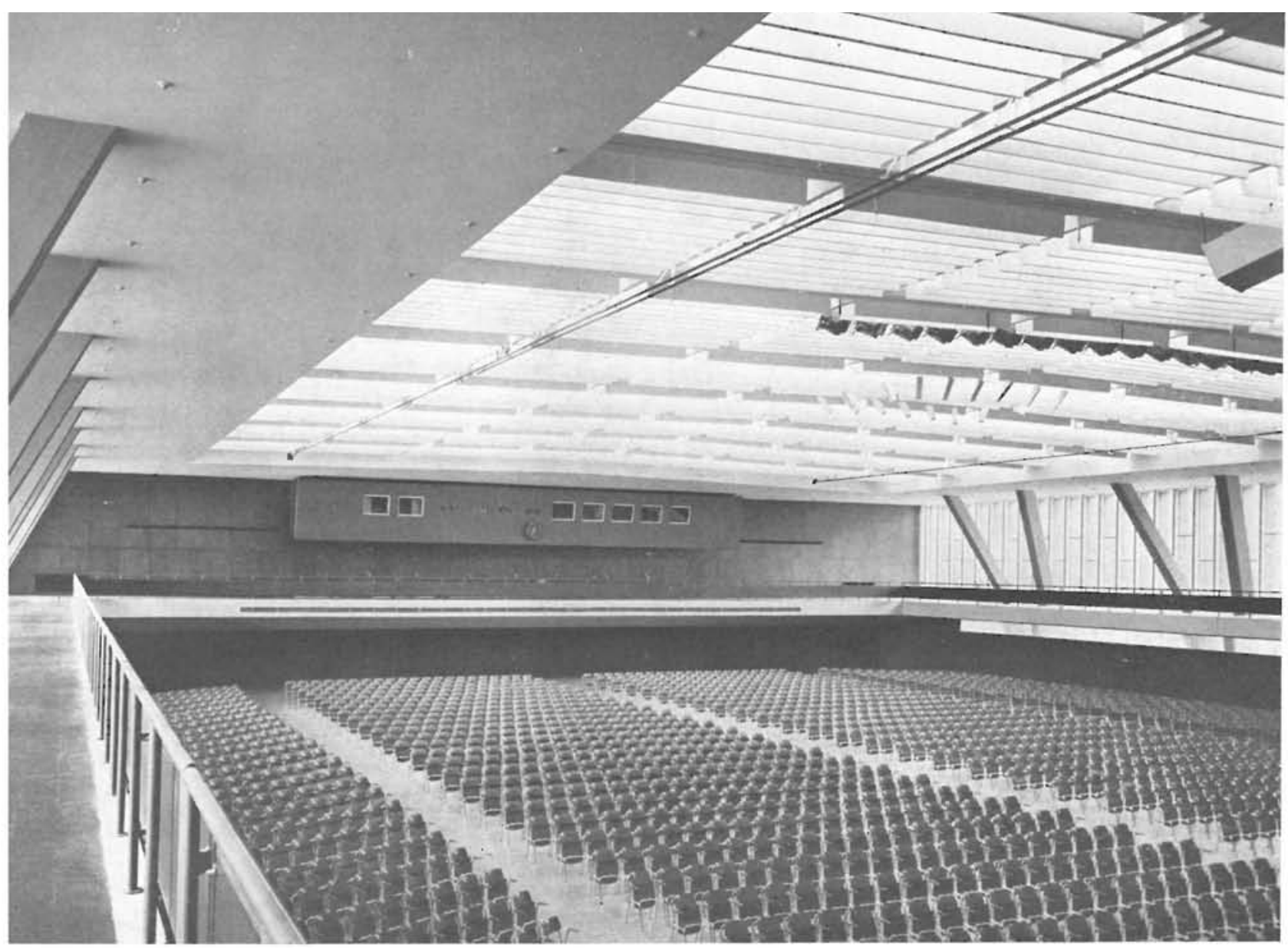

Fotos: HUGO SCHMÖZ y RUDOLF EIMKE

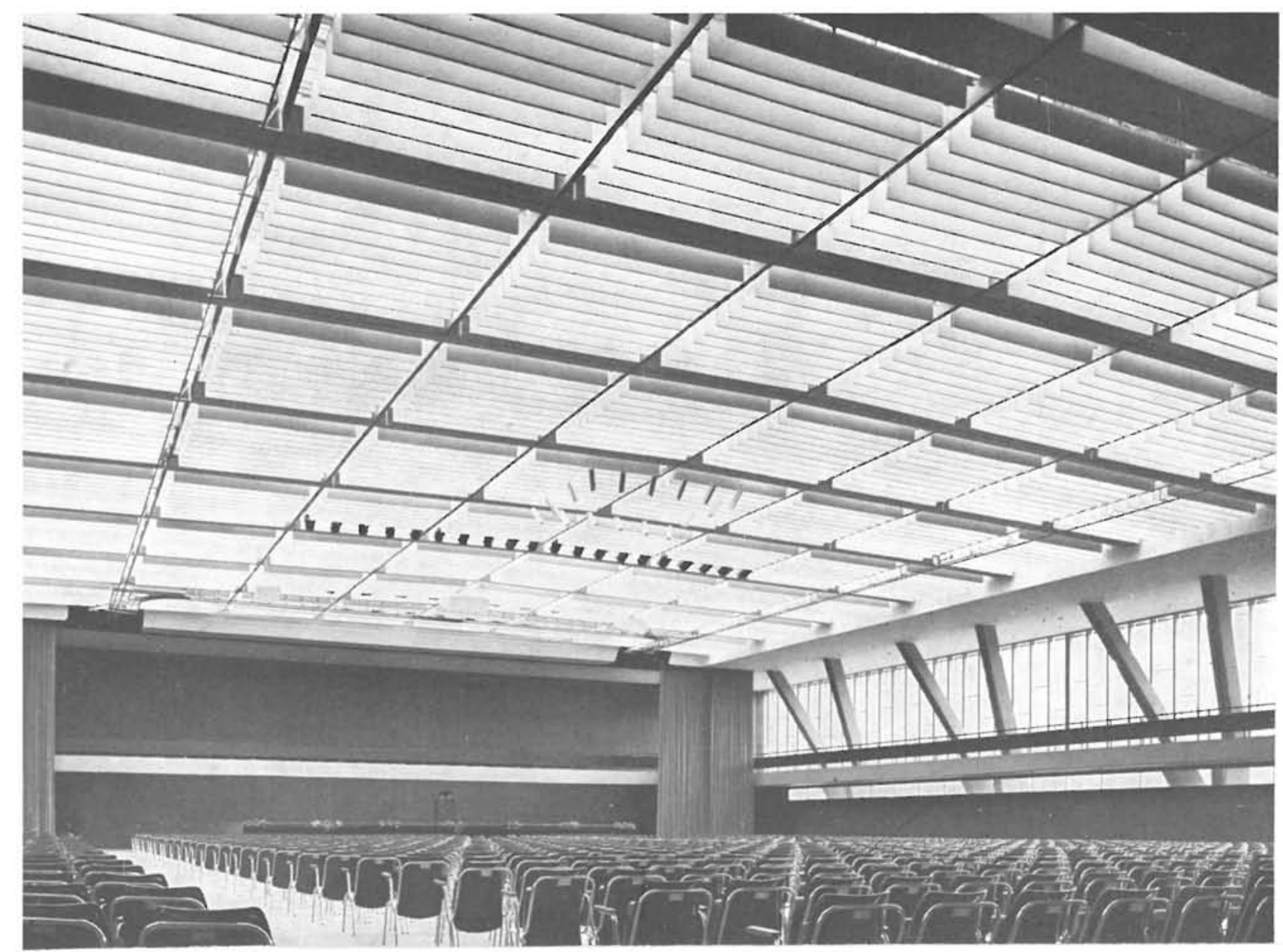




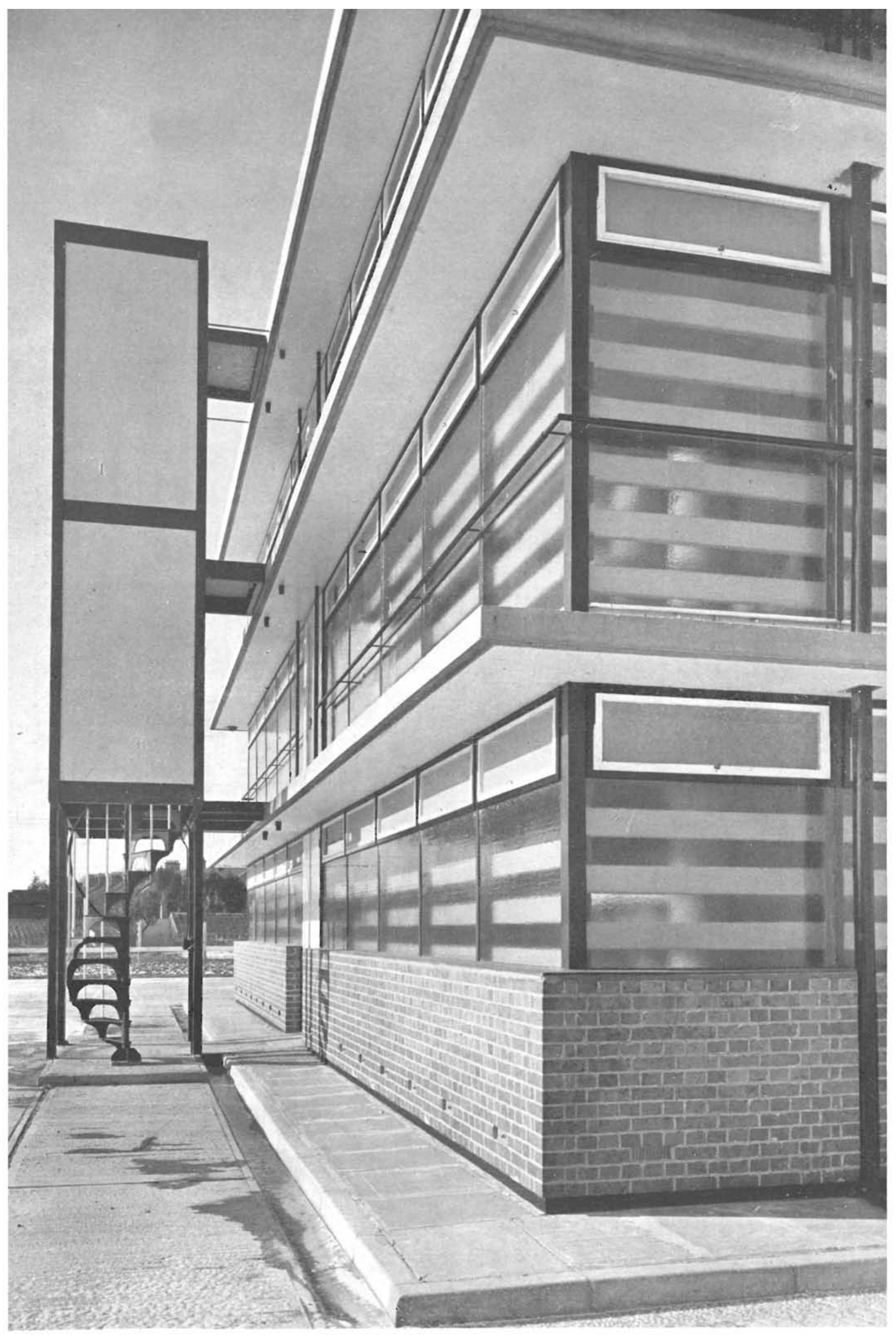

